\title{
Playing games for risk prevention: design, implementation and testing of serious games in recent European projects UPStrat-MAFA and KnowRISK
}

\author{
Stefano Solarino*,1, Gemma Musacchio ${ }^{2}$, Mónica Amaral Ferreira ${ }^{3}$ and Elena Eva ${ }^{1}$ \\ (1) Istituto Nazionale di Geofisica e Vulcanologia, Osservatorio Nazionale Terremoti, Italy \\ (2) Istituto Nazionale di Geofisica e Vulcanologia, Amministrazione Centrale, Italy \\ (3) Instituto Superior Técnico, University of Lisbon, ULisboa, CERIS, Lisbon, Portugal
}

Article history: received March 2, 2020; accepted January 29, 2021

\begin{abstract}
In the last decade, bottom-up strategies of risk education have raised importance, making serious games to become an alternative or complementary teaching tool for enhancing skills for a collaborative and adaptive response to social-ecological challenges.

This study describes issues and challenges of serious games implemented within the framework of two European projects, namely UPStrat-MAFA (Urban Disaster Prevention Strategies using Macroseismic Fields and FAult sources) and KnowRISK (Know your city, Reduce seISmic risK through non-structural elements); the goal is to instil in young people a proactive attitude towards the mitigation of seismic risk.

The games were tested in some dissemination events focussed on fostering seismic risk preparedness in students and improving good practices. We discuss the performance of our games even against more standard approaches to risk education. Our experience shows a rise of students' engagement compared to standard learning activities. The games were effective as students were able to grasp the most relevant actions to reduce risk.
\end{abstract}

Keywords: Serious games; Seismic risk mitigation; Prevention; Bottom up approach; Education.

\section{Introduction}

Despite the recent scientific and technological advances in disaster research studies and the potential improvement in the Disaster Risk Management (DRM hereinafter), the devastating impact of hazards shows that both concept and practice on preparedness are not adequately conveyed to society. Among the reasons for the gap between science and society, the standard top-down approach may play a crucial role. In this approach the decision making is centralized and managed by governments, without any real participation of the affected communities. This in turn often neglects local cultural roots or economic and social needs, causing communities exposed to risk to perceive these actions as inappropriate and potentially not useful [Solinska-Nowak et al., 2018]. 


\section{Stefano Solarino et al.}

The top-down approaches to mitigate risks are often bound to the concepts of "maintenance and protection" [Saban, 2014], lack of openness and adaptability of policies to local situations and, above all, to the fact that decisions are based on a low public participation. They often do not provide enough information about risks neither introduce the risk concepts into the national school curricula or do not enable individuals to be aware about potential risks and on how to mitigate them.

However, in the last decades, in the effort to at least partly overcome the limitations to effective risk communication and relief provision, bottom-up strategies of risk education have raised importance [Musacchio et al., 2015a]. The bottom-up approach is based on a paradigm shift towards more participatory and community-based DRM strategies. The main advantage is that end-users are treated not merely as a target audience but as partners in co-learning through processes and products that reflect their own contributions [Roncoli, 2006]. The participatory style of education has taken to use games/simulations as an alternative, or complementary, teaching tool to enhance collaborative and adaptive skills and response to social-ecological challenges. In fact, following the shift in DRM strategies, decision-making and practice, there is increased recognition [Gampell and Gaillard, 2016; Gampell et al., $2017,2019]$ that serious games (that is, games developed not just for entertainment) may serve as participatory tools, and support understanding of essential issues, such as sustainable development, climate-change mitigation and DRM activities [Solinska-Nowak et al., 2018]. Obviously, designing an education game requires additional issues than enjoyment, involvement, motivation and adrenaline. These games have specific targets (learn about a certain issue, understand how to protect or to avoid unwanted consequences among the others) so their design must take into account the motivation, the educative target and the necessary appeal to make them worth playing. The "game approach" to risk education demands thus to tailor products to the learning styles and capacities of the audience and have different impacts on specific groups of people. A proper calibration of the technical language and of the media to reach a target public may turn more successful an education campaign [Musacchio and Solarino, 2019].

For example, digital multimedia or internet outcomes are highly appealing to younger rather than older people as younger people ("digital natives") are more inclined to new technology than older generations. Angelovska [2019] recalls that in 2017 84\% of people not using the internet in Europe, which accounts for $16 \%$ of the total population, is aged 55-74 while Tapscott [1998] claims that children possess an intuitive, spontaneous relationship with digital technology. However, according to Buckingham, [2013] it is not the technology itself to establish a gap between generations but how it is used and the use it is made for. A notable exception are video and computer games. In fact, a research study suggests that the average age of game players is thirty-three [Entertainment Software Association, 2007], that means that also young adults may be involved in the learning through games strategy.

In this framework, games result to be an adequate choice when addressing risk communication to students and, more in general, the younger public. If teachers supplement the formal lessons with alternative methods and techniques, by playing a game, students may learn without even realizing they do it and, at the same time, have fun. The action of playing makes use of the most natural ability of the human brain to acquire knowledge effortlessly, somewhat "accidentally." Indeed, as highly interactive and social activities, games and simulations may trigger a positive emotional response in players that can make them a compelling, challenging, memorable and fun learning experience [Bachofen et al., 2012].

Serious games are designed to foster knowledge, learn about certain subjects and expand concepts. Their success is based on the fact that playing a game involves inductive reasoning, memory, concentration, often also teamwork and cooperation, which are all requisites of learning. Serious games and simulations have the potential to enhance the process of remembering information [Solinska-Nowak et al., 2018]. Thus playing a game can, under certain circumstances, improve or support the learning process.

Many research and governmental institutions designed educational games as a support to teaching and learning in a particular subject [Zirawaga et al., 2017]. Solinska-Nowak et al. [2018] provide an overview of 45 non-commercial digital and analogue serious games/simulations dealing with issues related to DRM. In some cases, they are deliverables of research projects and are hosted on governmental or institutional websites. Some of these games can be played online, and are single player. However, the most are face to face multiplayer with direct interactions games. Unfortunately, use of serious games in schools remains rare, and is unlikely to be integrated into the curriculum [Kirriemuir and Mcfarlane, 2004]. This was especially true in the early 2000, when teachers knew little about the digital world or at least much less than their students [Prensky, 2003]. Nevertheless, the inventory of serious games is increasing as the game for prevention approach spreads (http://www.seismo.ethz.ch/en/knowledge/miscellaneous/earthquake-games/ among the others). 
In this paper we describe how we designed serious games within two European Community funded projects, namely the UPStrat-MAFA [Urban Disaster Prevention Strategies using Macroseismic Fields and FAult Sources, 2012] and KnowRISK [Know your city, Reduce seISmic risK through non-structural elements, 2017]. In the UPStratMAFA, aiming at the implementation of innovative prevention approaches to consistently link prevention measures to preparedness and response needs [Musacchio et al. 2015a, b; Musacchio et al., 2017] the serious game TremeTreme ("Shake-Shake") was designed [Barreto, 2014; Barreto et al. 2014; Botelho, 2019]. Treme-Treme (www.treme-treme.pt) has a carefully thought-out educational purpose to improve student knowledge about earthquake science and preparedness in a fun way, appropriate for elementary school kids. In the KnowRISK project, a research program about Non Structural Damage (NSD hereinafter) and vulnerability during an earthquake, a few educational games to disseminate the results to students and to foster best practices were designed. In particular the "Do it right: be safer!" and the" Find the difference: be safer!" games will be described.

We here discuss the pros and cons of the approaches followed in each research project to design the games; we also estimate their impact in terms of preparedness within each project. Finally, we comment on the first feedback from the adoption of these tools to inform about disasters and foster disaster risk reduction (DRR hereinafter).

\section{The background: motivation for games in the UPStrat-MAFA and KnowRISK projects}

The UPStrat-MAFA project lasted two years between 2012 and 2013. It had a multi-disciplinary approach to disaster prevention that encompassed strategies based on the analysis of the level of risk and information [Musacchio et al., 2017]. The project strongly relied on prevention based on education and communication of risk. Analysis on the levels of education were performed and weaknesses recognized which contributed to identify needs and gaps, creating an opportunity to develop various educational tools such as a game-based learning or serious game for school children (Treme-Treme) and audio-video products for the general public, namely "Before it's too late" [2014].

The KnowRISK project (www.knowriskproject.com) took place between 2015 and 2017 and had communication as a primary goal. It aimed at helping European citizens and institutions to deal with the problem of performance of Non Structural Elements (NSE hereinafter) which under seismic loads may cause underestimated damage and affect resilience [e.g.: Lopes et al., 2018]. The project addressed schools [Musacchio et al., 2018 b], citizens and business groups [Musacchio et al., 2018 a] to be the relevant public to implement the communication action. A large part of the project activities was devoted to design tools able to foster preventative actions and best practices to different stakeholders (citizens and business groups). The risk communication strategy stood upon the concept of empower the different stakeholders, to increase information on a specific topic and to raise public awareness. In this framework, practical and easy to implement solutions to reduce vulnerability on NSE were provided and disseminated through several media. In particular, a Portfolio of solutions [Ferreira et al., 2018 a, b] for professionals and business groups, a Practical Guide [O'Neill et al., 2019] for citizens and the Students Short Guide were designed [Solarino et al., this issue]. They aim at raising awareness on risky situations concerning contents in business buildings, homes and schools respectively. The Practical and Students Short Guide show risky situations and indicate simple mitigation measures. The former aims at helping citizens to acquire and apply simple mitigation measures and describes how to render the own house more safe by doing actions of increasing difficulty and cost. It is designed as a path from a risky to a safer environment by moving, protecting, securing and retrofitting (Figure 1). Students Short Guide is devoted to students. It portrays familiar situations that pupils might be caught into while being at school: seismic shaking affecting a classroom, a science laboratory, the canteen, the gym dressing room and the office of the school's principal. Similarly, it addresses seismic shaking while being at home: in a bedroom living room, a kitchen, a bathroom or a balcony. The Practical Guide inspired the board game "Do it right: be safer!" while the Students Short Guide was used to develop the game" Find the difference: be safer!”.

The motivation for designing these games is straightforward. Most of the deliverables of the two projects are adult-oriented, whereas a great effort has been made to adapt them to a larger public by a large use of cartoons, little text with simplified and non-technical explanations. The most efficient way to transfer the contents of these deliverables, and thus the preventative actions and best practices, to a young audience has been to realize games. The simple rules of these games together with the fact that all may be played in teams or single players make them 


\section{Stefano Solarino et al.}

even more appealing. In particular, when teams are involved, a great stimulus to play and win is the competition among players. In turn, even players that may be not interested in the topic of the games may join to seek to win and have to learn. Moreover, all games can be played with or without the supervision of a teacher or an educator, making them playable in a variety of environments and situations.

By playing these games, the players are forced to imagine a scenario that resembles their classroom or their house. Such an approach is similar to that of other games and techniques, like the Virtual Reality [Lovreglio et al., 2017], that represent novel and effective alternatives to overcome the limitations of traditional approaches like evacuation drills, especially in buildings where such approaches cannot be easily implemented. Once they have found the right solutions for the game, they may transfer their acquired knowledge to their own environment and get, at least, a more expert view on the vulnerability of it.

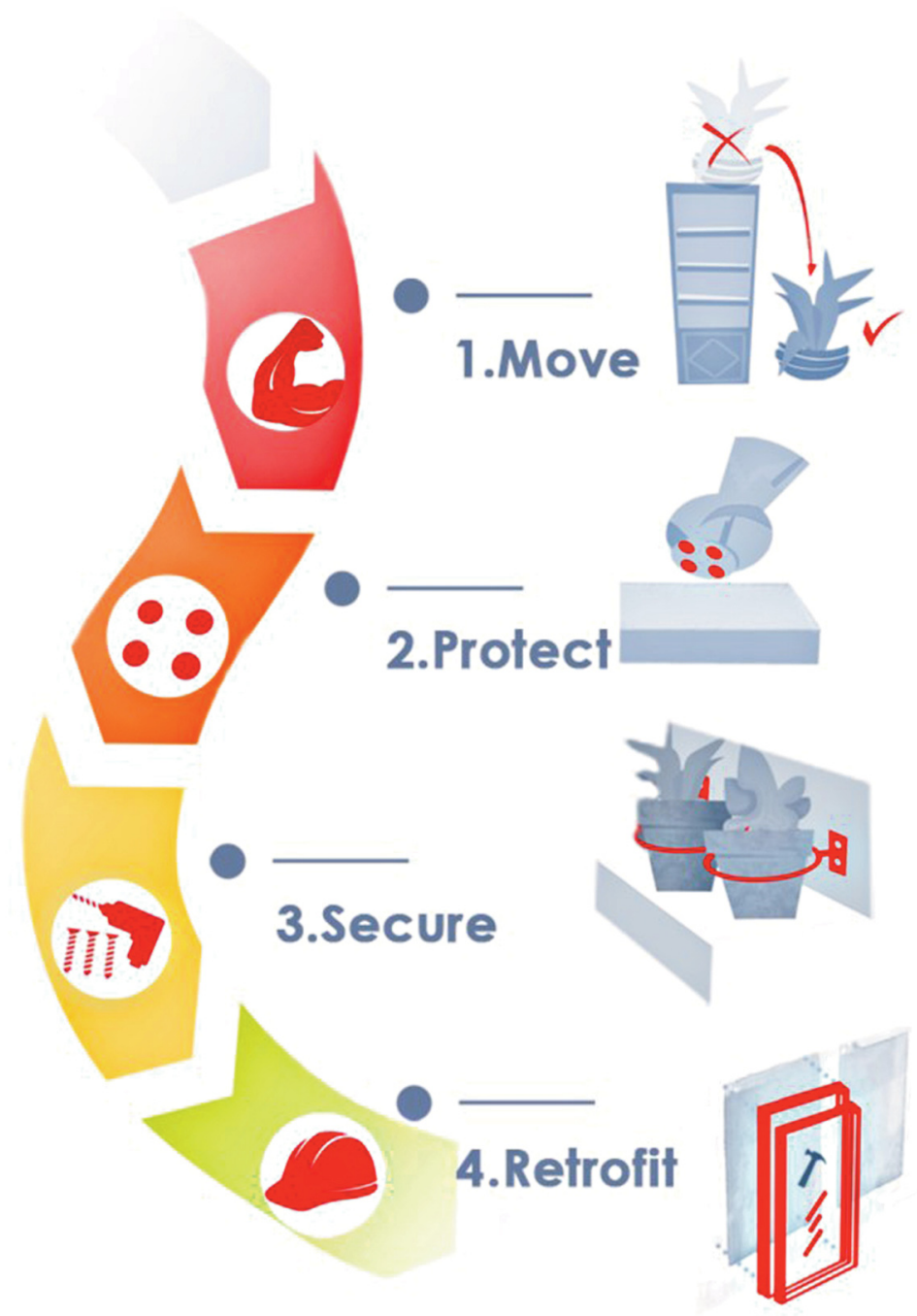

Figure 1. The Move-Protect-Secure-Retrofit concept as it is displayed in the Practical Guide.

\subsection{Description and rules of the games}

The games described in this work cover a wide variety of topics. They range from preparedness measures and proper behaviour during an earthquake (Treme-Treme) to preventative actions at home and in school (Do it right: 
be safer! and Find the difference: be safer!). Treme-Treme teaches how to reduce the risk of injury, how to react and be self-sufficient for up to three days during an emergency. Through the game, players learn about items needed for a disaster preparedness kit, as well as safe and dangerous locations of their home when an earthquake occurs. The other two games refer to non-structural damage on building contents. This is the damage easiest to mitigate: in most situations it does not require special skills or costs in order to be reduced. It therefore prompts actions that citizens and even young people could either undertake or promote.

The three games are designed for a wide range of ages. The Treme-Treme game is for elementary school age kids; the Find the difference: be safer! game is suitable for older children up to middle schools; the Do it right: be safer! game can be played by teens up to university age.

\subsubsection{Treme-Treme serious game}

Annetta et al. (2010) acknowledged that the design of a computer game offers players a way to build their knowledge and to develop new skills through its progression. Serious games are typically online applications that make use of the mechanisms of video games to communicate specific information (knowledge) that helps introduce relevant concepts and the application of those concepts to solve problems. They are designed for an educational rather than an entertaining purpose [Zyda, 2005; Nazry et al., 2017], integrating learning objectives into gameplay, through which educational aim is achieved. They stand on a simulation of a situation in the real world that triggers a problem solving attitude. The Treme-Treme game [Barreto, 2014; Barreto et al., 2014] developed by earthquake engineers, designers and computer engineers, under the UPStrat-MAFA Project, is a serious game where the real world situation refers to life in a seismic zone where an earthquake can occur at any time or it is actually striking when action happens. Avatars have to implement problem solving strategies in order to increase their safety to be prepared or to behave properly while the shaking is striking. Due to the fact that disaster risk education is frequently conducted by researchers and technical experts, with teachers and students rarely part of this discussion [Gampell et al., 2017; Petal, 2007], Treme-Treme was designed to be an effective learning tool and increase student knowledge about earthquake science and preparedness in a fun way (Figure 2), appropriate for elementary school age kids, as well as to encourage families and educators to talk about an emergency plan and a meeting place, how to react and what to do during and after an earthquake. It is an attractive learning approach that easily triggers student's interest and motivation. Since 2014, Treme-Treme has had a great reception; anyone could simply access (http://www.treme-treme.pt/) and play directly on the browser, or download to a computer. It can be played individually or by the whole class together or with family and friends. The game is available in Portuguese, English, Italian, French and Spanish and distributed free of charge on the website (www.treme-treme.pt) to more than 2000 visitors, and Google Play (since July 2020). Treme-Treme's Facebook page is also available to disseminate the educational game and to provide information related to the topic of seismic risk and preparedness. TremeTreme has been used in several Portuguese schools by elementary school teachers. Students play it individually or in groups of 2-3 in the school's computer room. When there is no computer room, teachers can use the projector or an interactive projector, and one or two class leaders play as the other classmates "say" what they should do. The possibilities to play it are endless. Several dissemination sessions have also been held in schools and events in Portugal, such as the exhibition” Quando Lisboa Treme. De 1755 à Cidade Resiliente”at Palácio Pimenta in 2015/2016; the "European Researchers' Night" and "Sons do Vale_Sustentabilis Festival” in 2016 and the "Avante Festival" in 2018. The game was also successfully used in schools for children with special needs, something that had not been foreseen initially. During these years and observing student's learning experience using TremeTreme, we realized that sometimes learners tended to concentrate on gameplay rather than learning, so a new version [Botelho, 2019] was developed. It allows researchers and teachers to track learning progress during the gameplay through quizzing with specific questions and rewards/incentives. The inclusion of a quiz at the end of each game level has a positive impact on students' engagement and motivation and also facilitates discussion about the incorrect responses.

This serious game does fill a gap, being fundamental to be maintained and improved so that Treme-Treme may continue to be played, fulfilling the objectives: training, learning, engaging and raising awareness. Notwithstanding all the success, a big challenge is to increase the popularity of Treme-Treme amongst school age children, educators, parents and policy-makers, in order to foster public awareness and engagement in risk education. 

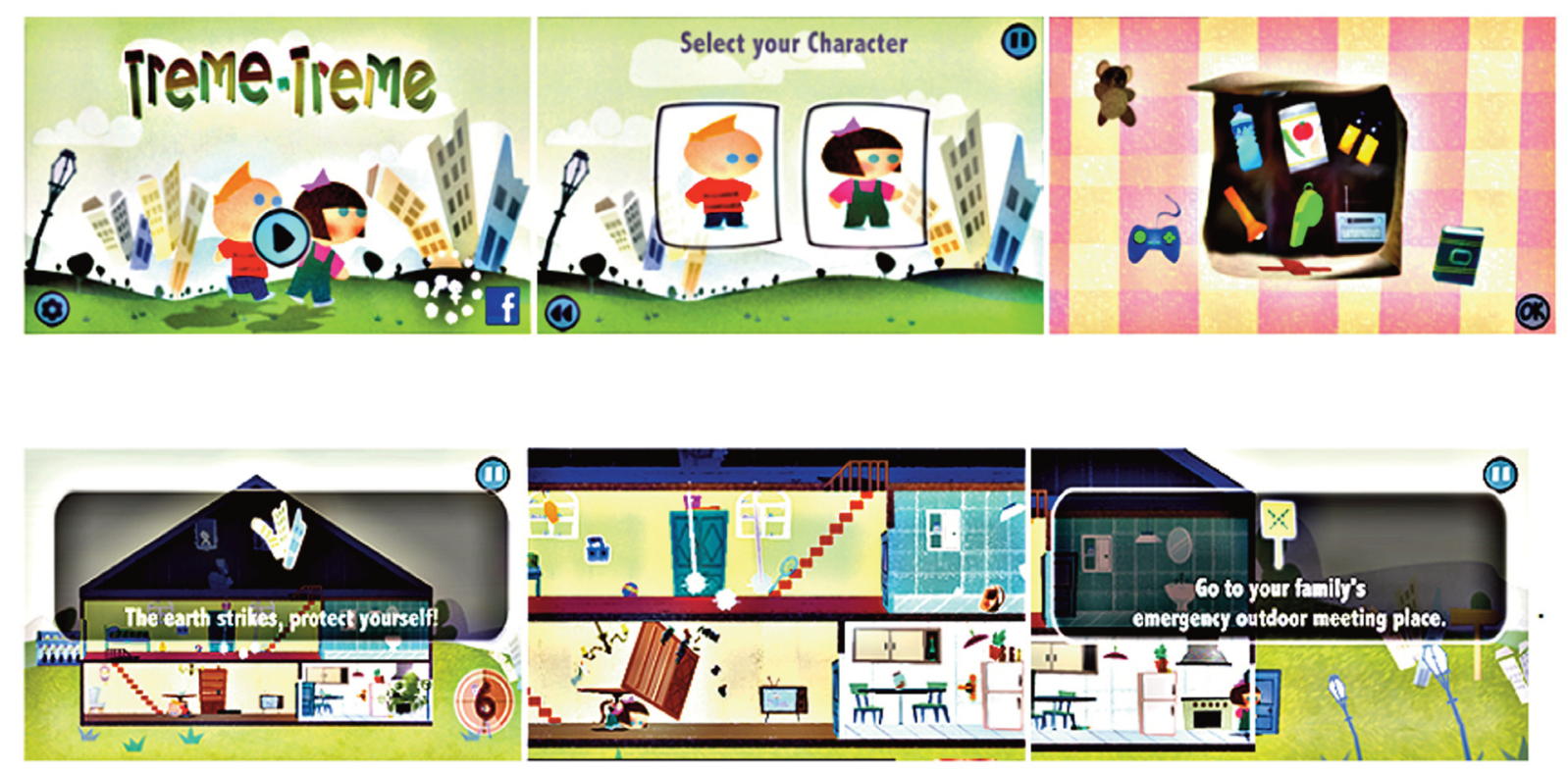

Figure 2. Treme-Treme serious game scenes. Sunami and Terramota teach what to do before, during and after an earthquake.

\subsubsection{Do it right: be safer!}

This is a board game basically representing an inquiry-based strategy to disseminate the best practices included in the Practical Guide for citizens. Best practices are essentially solutions to reduce NSE vulnerability of building contents, grouped according to a Move-Protect-Secure-Retrofit concept that highlights increasing efforts and costs to reach safety. It is based on experimental and computational research developed within the project to test and derive proper solutions for vulnerability of NSE. The Practical Guide is not meant to be a complete list of solutions, while it should be triggering a proactive attitude towards seismic risk and build capability to cope with the hazard. It was designed after a research analysis on needs, priorities and obstacles communities exposed to seismic hazards might have. However, even though carefully tailored to the purpose and to the public it remains a leaflet and, as such, it is not a tool meant for triggering discussion. The motivation for turning into a game was to increase its effectiveness by triggering discussion. For this reason, the game is played without providing detailed information on what could be done to reduce vulnerability to non-structural elements. It should only be given explanations on what are structural and non-structural elements of buildings and suggest strategies that could be undertaken to raise security in a house if one lives in an earthquake prone area.

The Practical Guide was then turned into three type of cards: 23 solutions' cards depict actions to decrease building contents' vulnerability; 4 needs cards show the needs in terms of the costs and level of expertise; 4 avatars cards are the characters that players can choose to be, namely a seismologist, an engineer, a civil protection officer, a fireman (Figure 3).

The solution cards and the needs cards have the same graphic concept of the Practical Guide: in red colour are the vulnerability issues (cross marked), the suggested solutions (V marked) and the needs in terms of costs, efforts (Figure 4). Four boards are the solutions' boards (Figure 5c) where cards should be properly laid: they are colour coded according a traffic-light concept (red-orange-yellow-green) matching that of the Move-Protect-SecureRetrofit. These boards have icons showing the needed tools and anchoring items.

Four wrong solutions, one for each of the four preventative actions, Move-Protect-Secure-Retrofit, are included within the solutions' cards (Figure 5). They increase challenges of the game and might trigger discussion.

The players are teamed in two groups and a moderator presents the game, the scientific and the best practice background framework. Key issues to be discussed before starting the game are: (1) earthquakes cannot be prevented, but losses can be successfully reduced; (2) if one lives in any area prone to seismic hazard he is exposed to injuries, damage and long-term financial consequences; (3) therefore one must take action to reduce vulnerability of his house. 


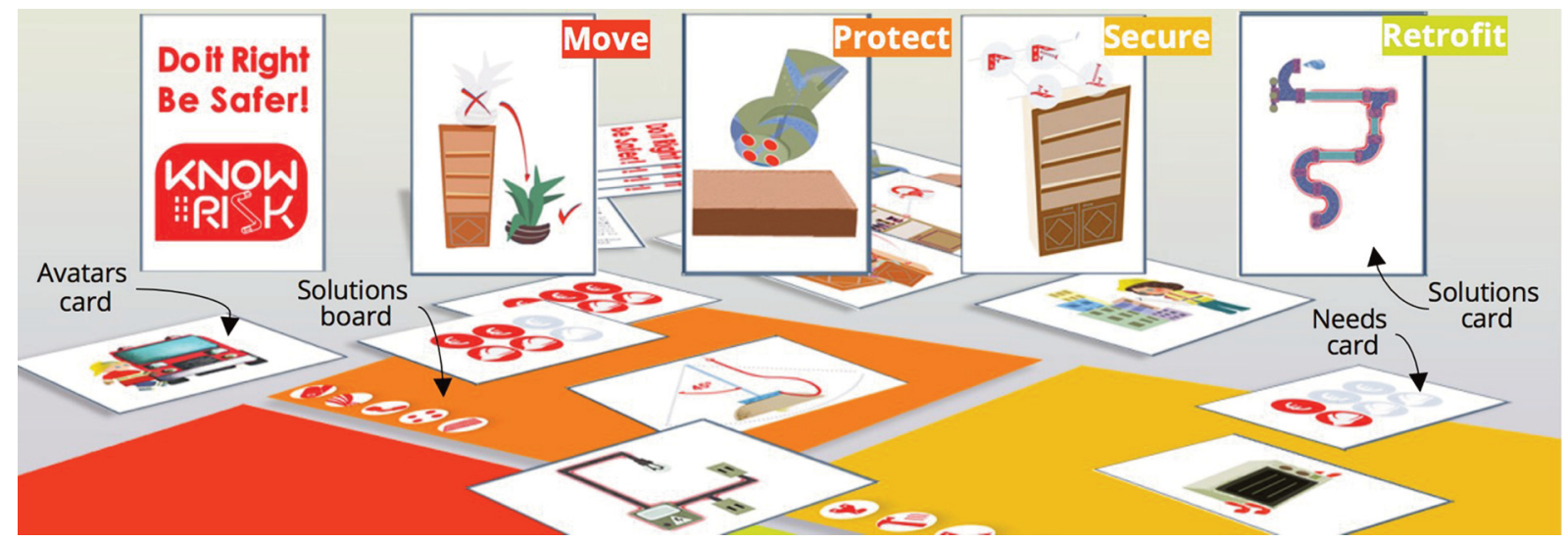

Figure 3. A snapshot of the board game "Do it right: be safer!" The Move-Protect-Secure-Retrofit concept is colour coded. Solutions, Needs and Avatars cards, and the Solutions boards are displayed.

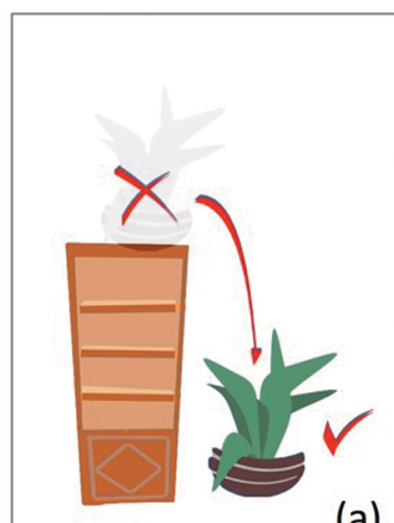

(a)

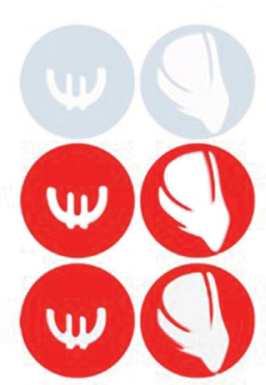

(b)

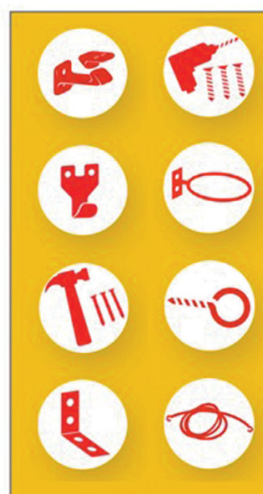

(c)

Figure 4. (a) Example of solution card where in red are vulnerability issues and do-it-yourself suggestions on how to secure building contents; (b) needs cards where in red are the necessary money and level of expertise; (c) an example of the solutions' board for the vulnerability measures concerning: yellow is for the secure concept. The board is where the cards should be laid. Red icons suggest tools and anchoring items.
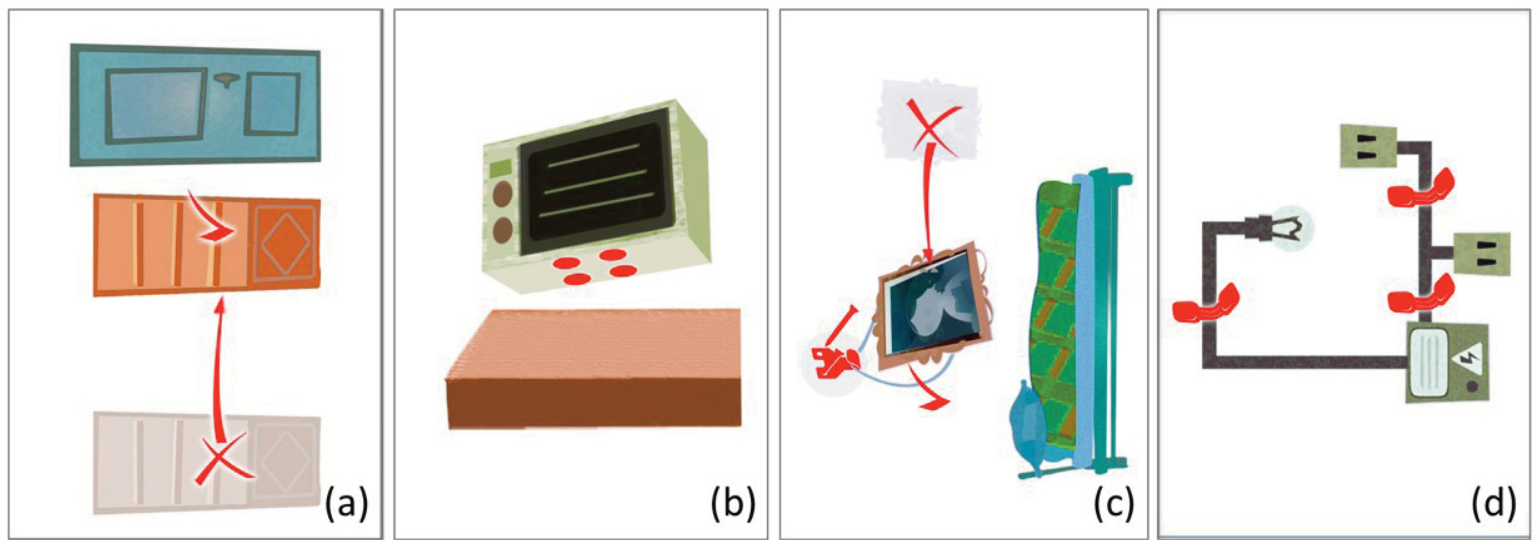

Figure 5. The 4 cards presenting wrong solutions in the "Do it Right: be safer!" game. From left to right: a bookshelf should not be moved next to a door (a); the microwave is not efficiently protected (b); a heavy frame is very well secured but still above a bed (c); the gas line is only secured instead to be retrofitted (d). 


\section{Stefano Solarino et al.}

It is expected of the moderator to engage discussions, give reasons and motivate the public towards proactive attitude.

The board game is annexed to this paper as supplementary material. The game was tested within several risk communication initiatives, both in Italy and Portugal: in the classroom, in Science Festivals and in open-doors events (Figure 6).
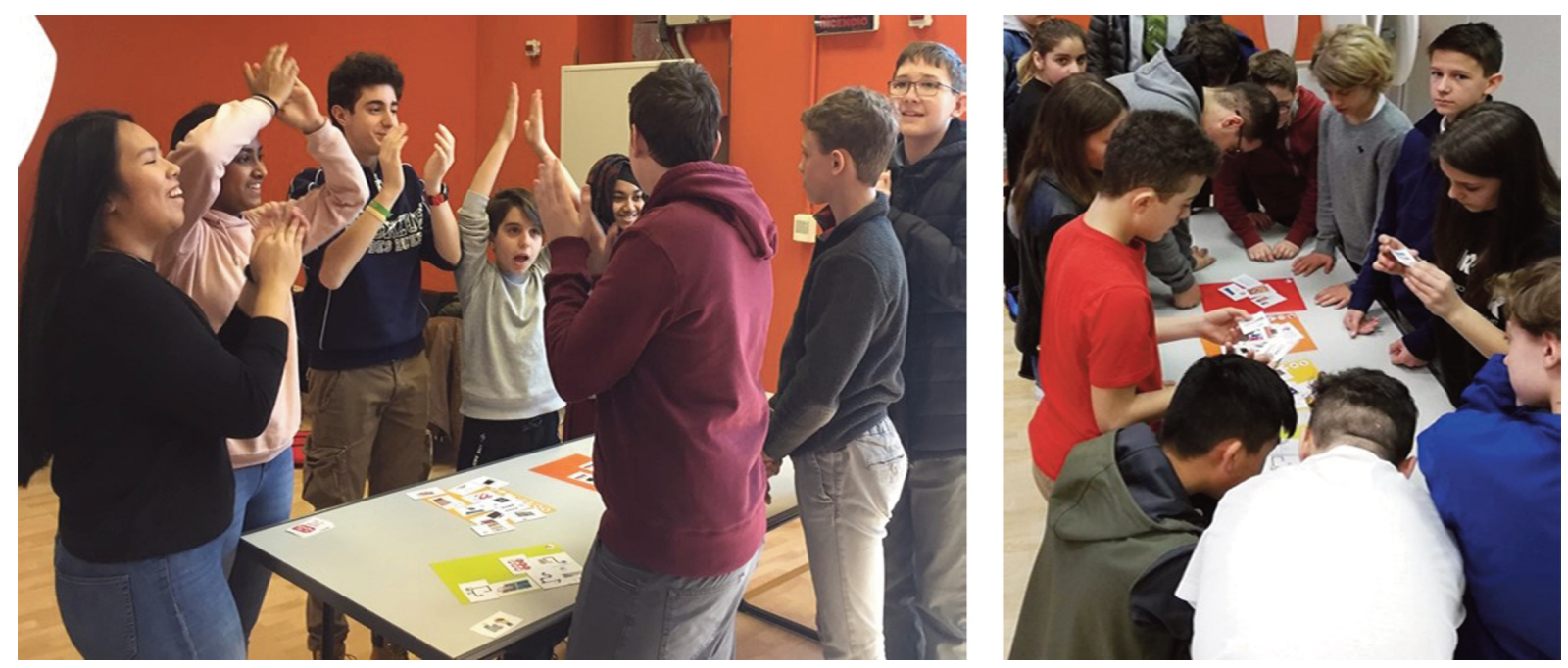

Figure 6. Do it right: be safer! Played during ScienzAperta 2018, last open-doors event within the KnowRISK project.

\subsubsection{Find the difference: be safer!}

This game stands upon the SSG developed under the KnowRISK project to raise attention towards preventative best practices in young students. It is entirely graphic: attractive drawings show the effect of earthquake shaking on familiar environments with and without solutions to reduce NSE vulnerability of building contents. In this game there is no conceptual message or color coding: Move-Protect-Secure-Retrofit concept is not explicit. It is only printed as a background message that is meant to help the student think about what and eventually why and how vulnerability of non-structural elements was and could be mitigated.

The two chosen environments are a kids' bedroom and a school room (Figure 7). Details in drawings are only apparently overwhelming. They actually help kids to feel the environment as a living lab where they can imagine having the experience of the earthquake shaking and, yet, they can count on their ability to solve a problem.

The game can be played either in small groups, by using boards displaying the two environments, or with a classroom as a whole, by plotting on a wall board the two images. The kids are asked to spot the difference before and after solutions to reduce vulnerability of NSE and explain the reason for their choice.

We tested the game in schools (Figure 8) within the risk communication protocol that was implemented during the KnowRISK project [Musacchio et al., this issue].

Discussion is usually sparkling and kids tell their own story on their experience or on the situation in their own bedroom. They happen to check their classroom to verify if it is safe.

\section{Discussion and conclusions}

Much of the content that students need to learn is not motivating for them. It is probably safe to say that today's teachers, trainers, and educators are rarely as effective as they might be in the motivational realm, and this often causes difficulties in convincing otherwise highly stimulated students to learn [Prensky, 2003]. This is particularly an issue in the field of disaster risk mitigation where the involvement of young people cannot be neglected since, in an emergency, they are among the most vulnerable people. 


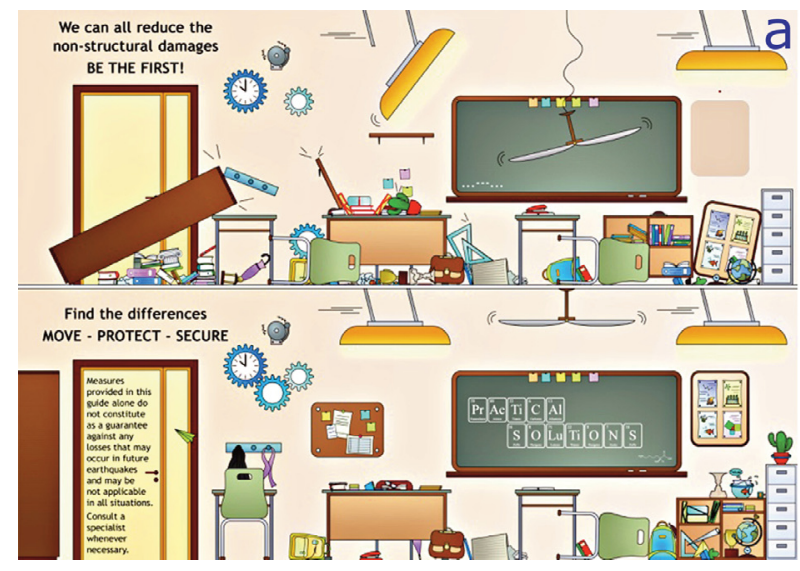

a)

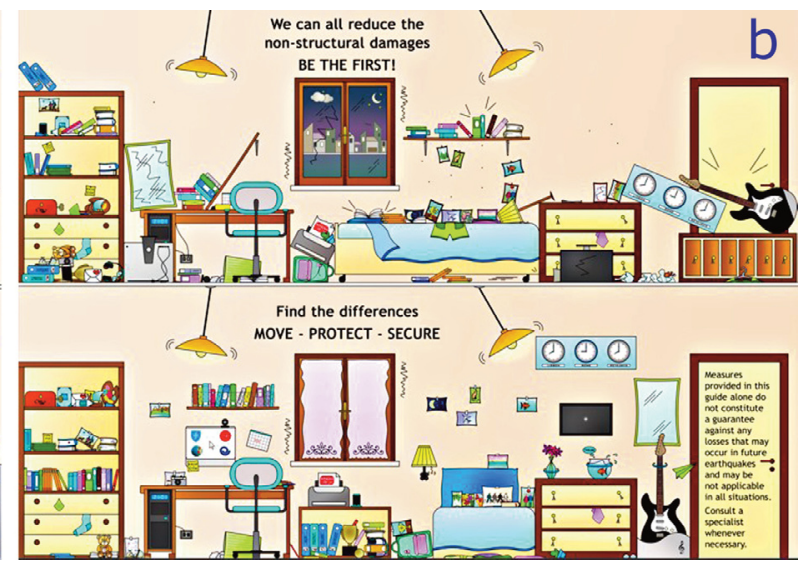

b)

Figure 7. Images from the game Find the difference: be safer! (a) kid's bedroom and (b) a classroom. Both images represent possible situations before (upper panel) and after (lower panel) solutions to reduce vulnerability of NSE in a familiar environment.

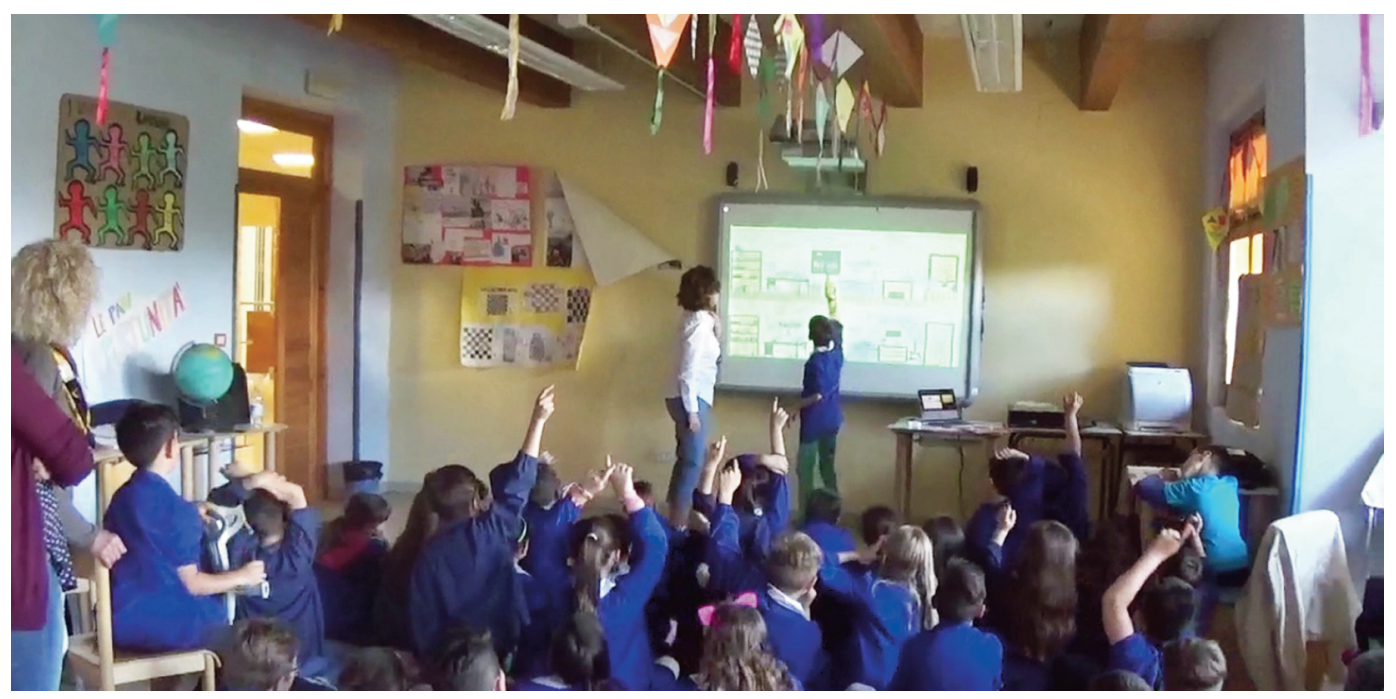

Figure 8. Find the difference: be safer! discussion with an elementary school's classroom.

Serious games are a clever way to convey scientific concepts and to teach best practices [Musacchio et al., 2015c] to the public. They rely on a participatory approach where students often interact with scenarios that are not common in everyday life like a big earthquake, a tsunami or an unsustainable increase of the temperature at a worldwide scale. These games can be included in the edutainment activities that are both educational and enjoyable, although this definition mainly applies to tv programs or software. In this approach the educational messages are hidden under a form of entertainment very familiar to people and, as a consequence, appealing and natural for them. In this perspective, games have a strong potential to fill the gap among adults, teens and children in any educational campaign. If carefully designed, they may make the difference between just adequate and highly effective communication through motivated and emotional involvement.

In this paper we have described the serious games implemented in two recent projects, namely the UPStrat-MAFA and KnowRISK programs. In overall the games cover a wide range of ages, each one being specific for different groups of students from elementary schools to university and are mainly devoted to seismic prevention. The games were played in several science outreach events such as ScienzAperta ("Open Science”), the Genoa Science Festival, in museums and in a few schools in the frame of the educational activities that the authors usually carry out (both in 


\section{Stefano Solarino et al.}

Portugal and Italy), reaching a few thousand students. Since the games can be downloaded on the internet, we believe that the number of people involved will grow, although this may not correspond to the same number of players.

We here discuss the pros and cons of our approach and we try to estimate the impact of our games on the path to preparedness and safety. Many authors agree on the role and added value of serious games in the field of natural risks. For example, Solinska-Nowak et al., [2018], state that DRM-related serious games/simulations offer a rich social experience with players collaboratively solving a problem. However, authors highlight that it is not straightforward to quantitatively estimate the improvement in the learning process due to the contribution of serious games. The research studies by Djaouti et al., [2011], Ulrich, [1997], Di Loreto et al., [2012], among the others have proven that little insight is available via either developers or users regarding the effectiveness of games. These limitations apply to our games too. In particular, it is very difficult to estimate any long-term evaluation of the activities' impact.

A simpler issue is to evaluate the impact of our games on the awareness and preparedness of the players versus a "standard" approach (e.g. frontal teaching, scientific conference). We first discuss this in a quantitative way and then in an experience-based perspective.

During the outreach event "ScienzAperta" middle and high schools' students attend a series of activities that include short conferences, laboratories and games. In 2018, the closing activity consisted in playing "Do it right, be safer" (figure 6). We submitted to our visitors a questionnaire (Musacchio et al., this iusse) aiming at exploring their knowledge, attitude and practice on how to mitigate non-structural damage before $\left(T_{0}\right)$ and after $\left(T_{1}\right)$ their participation in the game. It must be remarked that the differences in the answers in the questionnaires, which are shown in figure 9, are due to the overall outreach event since the contribution of the game itself cannot be extrapolated. However, the game was the only activity that dealt with specific issues concerning non-structural elements. The concept behind the game was that actions can be linked to a path of increasing efforts. Figure 9 shows that students grasped the idea that just lowering a heavy object or securing items to the wall to prevent tumbling is a worthwhile and effective effort towards risk reduction.

One additional way to estimate the impact of our serious games is based on the examination of the attitude of students during the game compared with the "standard" learning activity (e.g. a conference). This review does not give insight on the improvement of the learning process but, as shown by many authors, the amount of participation and the emotional engagement, which cannot be estimated if not by a visual analysis, are requisites for a motivated learning. In playing a game students are able to freely express their ideas and knowledge although they are in a formal environment as the classroom can be.

In particular, there are few aspects that deserve attention:

- games trigger discussion among players more than a regular lesson or talk. Discussion is always positive since usually within a game framework there is a peer engagement approach: different points of view are shared by someone at the same level. Often it is not easy to explain a personal point of view to a teacher or a parent while it is much easier to a classmate.

- games establish a fruitful competition, that in turn summons even those students that would not participate in group activities.

- games make people ponder more on answers. Since making a wrong choice or giving a wrong answer may disadvantage the team or the player itself, answers are pondered more than in a normal interview. This has in turn a deeper impact on memory and knowledge.

- games make people reflect on errors. Again, the structure of the game makes people think about the errors and distinguish-remember the correct answer.

- information given by games based on visual displays are easier to remember.

Our experience with serious games is then very encouraging. We strongly believe that the motivation as provided by games is a key point to foster education, given that the message to be conveyed is sound and adequately formatted. However, as stated by Solinska-Nowak et al., [2018], regardless of their many advantages, serious games/simulations cannot be treated as a standalone disaster-awareness raising tool. Therefore, more detailed information on mechanisms of hazards, exposure and vulnerabilities should be provided to participants even in more traditional formats. 


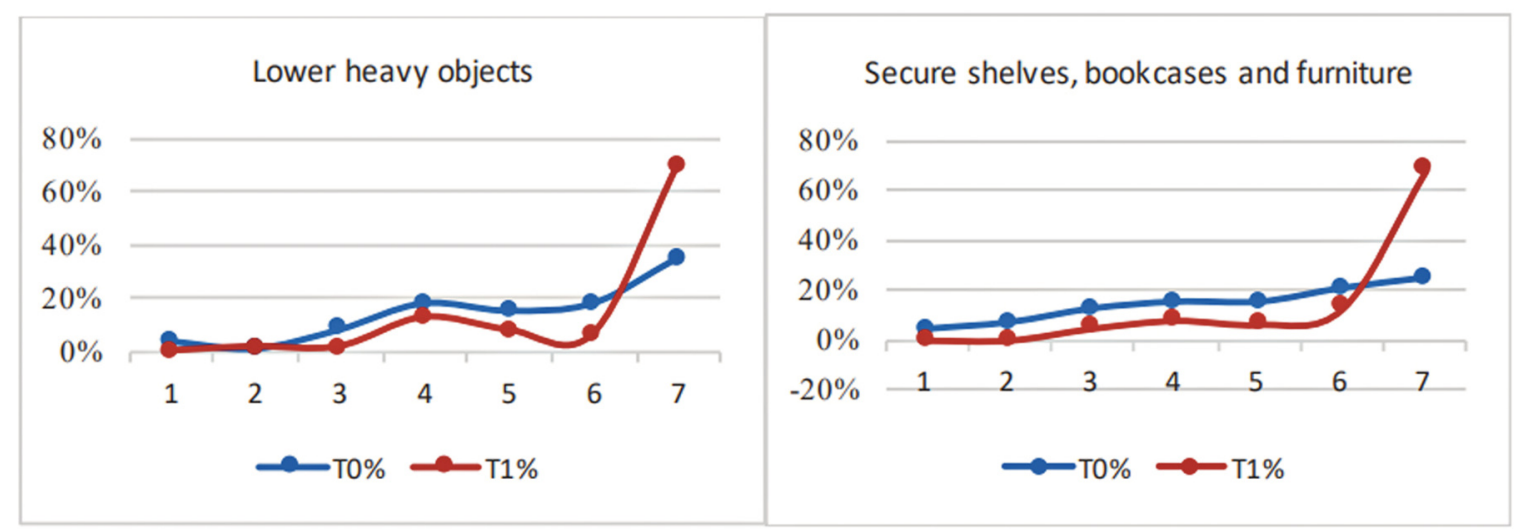

Figure 9. Quantitative assessment of effectiveness for the Do it Right: be safer! and Find the difference: be safer! The diagrams plot the answers to the following two questions: "rate the importance, in reducing vulnerability to NSE, to lower heavy objects (left); "rate the importance, in reducing vulnerability to NSE, to secure heavy objects"(right). The percentage of answers over the total are shown at $\mathrm{T}_{0}$ (before) and $\mathrm{T}_{1}$ (after) gaming; 1-to-7 are Likert- type [Likert, 1932] scale grades from 1=not-important to $7=$ very-important.

Acknowledgements. KnowRISK is co-financed by European Commission's Humanitarian Aid and Civil Protection Grant agreement ECHO/SUB/2015/718655/PREV28. It is a project that involved four different European research centres and universities under the coordination of the Instituto Superior Técnico (Portugal). The partners are the Istituto Nazionale di Geofisica e Vulcanologia (Italy), the Laboratório Nacional de Engenharia Civil (Portugal) and the Earthquake Engineering Research Centre (University of Iceland). We acknowledge all the participants of KnowRISK group for the fruitful discussions and support.

\section{References}

Angelovska, N. (2019). 16\% Of Europeans Don't Use The Internet. Who Are They? Forbes. https://www.forbes.com/sites/ninaangelovska/2019/01/31/16-of-europeans-dont-use-the-internet-who-arethey/?sh=46f4e14653b0

Annetta, L., E. Folta, M. Klesath (2010) V-learning: distance education in the 21st century through 3D virtual learning environments. Springer, Netherlands, 182.

C. Bachofen, P. Suarez, M. Steenbergen, N. Grist. (2012). Can games help people manage the climate risks they face? The participatory design of educational games, Red Cross Red Crescent Climate Centre, 2012.

Barreto, P. (2014). Treme-treme - A serious game to teach children earthquake preparedness, MSc Thesis, Instituto Superior Técnico, Universidade de Lisboa.

Barreto P., R. Prada, P.A. Santos, M.A Ferreira, H. O’Neill, C.S. Oliveira. (2014). A serious game to teach children earthquake preparedness, in: Proceedings of conference of science and art of video games, Videojogos 2014, November 6-7, Barcelos, Portugal

Before it's too late (2014).

https:/www.youtube.com/watch?v=ENemjLfByzU\&fbclid=IwAR0JpMbciBieWnSEZP9dVnWP2xoxiLpwh0hz iySOFuuAwfvUqcv-BH80OvA, https://www.youtube.com/channel/UCg0VxYGPYa2bUGXIhZl35zQ

Botellho, D.N.G. (2019). Treme-Treme 2.0 - A serious game to teach children earthquake preparedness, MSc Thesis, Instituto Superior Técnico, Universidade de Lisboa.

Buckingham D., (2006). Digital Generations. eds. Buckingham and Willett, Erlbaum 2006, 1-14, ISBN 0-8058-5980-2, https://doi.org/10.4324/9780203810668

Di Loreto, I., S. Mora, M. Divitini (2012). Collaborative serious games for crisis management: an overview, in: 21 st International Workshop on Eenabling Technologies: Infrastructure for Collaborative Enterprises, 352-357. 


\section{Stefano Solarino et al.}

Djaouti, D., J. Alvarez, J. Jessel, O. Rampnoux (2011). Origins of serious games, in: M. Ma, A. Oikonomou, L.C. Jain (Eds.), Serious games and edutainment applications, Springer, 25-43, https://doi.org/10.1109/WETICE.2012.25.

Entertainment Software Association (2007). Sales, Demographic and Usage data. Essential facts about the computer and video game industry, https://www.org.id.tue.nl/IFIP-TC14/documents/ESA-Essential-Facts-2007.pdf

Ferreira M.A., S. Solarino, G. Musacchio, F. Mota de Sá F, C.S. Oliveira, M. Lopes, H. O’Neill, L. Orlando and M.M. Faggioli (2018a). KnowRISK tools for preparedness and community resilience: Practical Guide, Short Guide for Students, Portfolio and Video, in Proceedings of the 16th European Conference on Earthquake Engineering, 18-21 June 2018, Thessaloniki, Greece.

Ferreira, M.A., C.S. Oliveira, F. Mota de Sá, M. Lopes, I. Pais (2018b). KnowRISK Portfolio of solutions: for the reduction of seismic risk through non-structural elements (available:

https://knowriskproject.com/portfolio/)

Gampell, A. and J. C. Gaillard (2016). Stop Disasters 2.0: video games as tools for disaster risk reduction, Int. J. Mass Emergencies Disaster, 34 (2), 283-316.

Gampell, A., J.C. Gaillard, M. Parsons and K. Fisher. (2017). Beyond Stop Disasters 2.0: an agenda for exploring the contribution of video games to learning about disasters, Environmental Hazards, 17, 2, 180-191.

Gampell, A.V., J.C. Gaillard, and M. Parsons (2019). On the use of participatory methodologies for video game research: Exploring disaster risk reduction in video games. Methodological Innovations, September-December 2019, 1-15, doi/10.1177/2059799119884277

Kirriemuir, J. and A. Mcfarlane (2004). Literature Review in Games and Learning hal-00190453, https://telearn.archives-ouvertes.fr/hal-00190453

KnowRISK (2017). Know your city, Reduce seISmic risK through non-structural elements. European Commission's Humanitarian Aid and Civil Protection Grant agreement ECHO/SUB/2015/718655/PREV2, www.knowriskproject.com

Likert B. (1932). A technique for the measurement of attitudes, Archives of Psycology, 140, 1-55.

Lopes M., A. Goretti, F. Mota De Sá, M.A Ferreira, C.S. Oliveira, C. Oliveira, F. Meroni, T. Squarcina, G. Musacchio (2018). Earthquakes in central Italy in 2016: comparison between Norcia and Amatrice; 16ECEE conference, Tessaloniki 18-21 June 2018.

Lovreglio, R., V., Gonzalez, R. Amor, M. Spearpoint, J. Thomas, M. Trotter and R. Sacks (2017). The Need for Enhancing Earthquale Safety by Using Virtual Reality Serious Games. Lean and Computing in Construction Congress (LC3): Volume I Đ Proceedings of the Joint Conference on Computing in Construction (JC3), July 47, 2017, Heraklion, Greece, 381-389, http://itc.scix.net/paper/lc3-2017-058.

Musacchio G., Falsaperla S., Bernharðsdóttir A.E., Ferreira M.A., Sousa M.L., Carvalho A. and Zonno G. (2015a) Education: can a bottom-up strategy help for earthquake disaster prevention? Bulletin of Earthquake Engineering, DOI: 10.1007/s10518-015-9779-1.

Musacchio G., S. Falsaperla, F. Sansivero, M.A. Ferreira, C.S. Oliveira, R. Nave and G. Zonno (2015b) Dissemination strategies to instil a culture of safety on earthquake hazard and risk. Bulletin of Earthquake Engineering, DOI:10.1007/s10518-015-9782-6.

Musacchio G., G. L. Piangiamore, G. D’addezio, S. Solarino and E. Eva (2015c). “Scientist as a game”: Learning geoscience via competitive activities, Ann.Geophys., DOI: 10.4401/ag-6695.

Musacchio G., M. A. Ferreira, F. Meroni, R. Rupakety, C.S. Oliveira and G. Zonno (2017). Urban Disaster Prevention Strategies in the UPStrat-MAFA project: from risk analysis to communication, in: Earthquake Engineering and Structural Dynamics in Memory of Ragnar Sigbjörnsson, Geotechnical, Geological and Earthquake Engineering, R. Rupakhety, S. Ólafsson (eds.), 44, DOI:10.1007/978-3-319-62099-2_17.

Musacchio, G., S. Falsaperla, G.L. Piangiamore, S. Solarino, M. Crescimbene, N.A. Pino, E. Eva, F. Manzoli, M. Butturi, M. Fabbri and M. Accardo (2018a). KnowRISK on Seismic Risk Communication: the set-up of a participatory strategy- Italy Case study. In: R. Rupakhety · S. Olafsson and B. Bessason, Proceedings of the International Conference on Earthquake Engineering and Structural Dynamics, Geotechnical, Geological and Earthquake Engineering, Springer International Publishing AG, 47, 413-429.

https://doi.org/10.1007/978-3-319-78187-7_31

Musacchio, G., E. Eva and G.L. Piangiamore (2018b). The KnowRISK Action for Schools: A case study in Italy. In: R. Rupakhety - S. Olafsson and B. Bessason, Proceedings of the International Conference on Earthquake Engineering and Structural Dynamics, Geotechnical, Geological and Earthquake Engineering, Springer 
International Publishing AG, 47, 459-471. https://doi.org/10.1007/978-3-319-78187-7_34

Musacchio, G. and S. Solarino (2019). Seismic risk communication: an opportunity for prevention, Bollettino di Geofisica Teorica ed Applicata, doi:10.4430/bgta0273.

Musacchio, G., E. Eva, M. Crescimbene, N.A. Pino and L. Cugliari (2021). A protocol to communicate seismic risk in schools: design, test and assessment in Italy, Ann. Geophys., 64, (this issue).

Nazry, N., M. Nazrina and D. M. Romano, (2017). Mood and learning in navigation-based serious games, Computers in Human Behaviour, 73, 596-604, 2017.

O’Neill, H., M. A. Ferreira, C. S. Oliveira, M. Lopes, S. Solarino, G. Musacchio, P. Candeias, M. Vicente, and D.S. Sousa (2019). KnowRISK Practical Guide for Mitigation of Seismic Risk Due to Non-structural Components, In Proceedings of the International Conference on Earthquake Engineering and Structural Dynamics. Geotechnical, Geological and Earthquake Engineering, Rupakhety, R., Olafsson, S. and Bessason, B. Editors, Vol 47., 309-321.

Petal, M. (2007). Disaster risk reduction education: Material development, organization, evaluation, Regional Development Dialogue, 28, 2, 1-25.

Prensky, M. (2003). Digital Game-Based Learning. ACM Computers in Entertainment, 1, 1, Book 02, 1-4.

Roncoli, C. (2006). Ethnographic and participatory approaches to research on farmers' responses to climate predictions, Clim. Res. 33, 1-99.

Saban, L.I. (2014). Disaster Emergency Management. The Emergence of Professional Help Services for Victims of Natural Disasters. Sunny Press, 242.

Solarino, S., Amaral Ferreira, M., Musacchio, G., Rupakhety, R., O’Neill, H., Falsaperla, S., Vicente, M-, Lopes, M., and C. Sousa Oliveira (2021). What scientific information on the seismic risk to non-structural elements do people need to know? Part 2: tools for risk communication, Ann. Geopys., 64, (this issue).

Solinska-Nowak, A., P. Magnuszewski, M. Curl, A. French, A. Keating, J. Mochizuki, W. Liu, R. Mechler, M. Ulakowska and L. Jarzabek (2018). An overview of serious games for disaster risk management - Prospects and limitations for informing actions to arrest increasing risk, International Journal of Disaster Risk Reduction, 31, 10131029, https://doi.org/10.1016/j.ijdrr.2018.09.001.

Tapscott, D. (1998) Growing Up Digital: The Rise of the Net Generation, New York: McGraw Hill.

Ulrich, M. (1997). Games/simulations about environmental issues existing tools and underlying concepts, In: Proceedings of the 28th Annual International Conference of the International Simulation and Gaming Association (ISAGA), July 1997, Tilburg, The Netherlands, 301-311.

Urban disaster Prevention Strategies using MAcroseismic Fields and FAult Sources- UPStrat-MAFA (2012), Grant Agreement No. 23031/2011/613486/SUB/A5.

Ziragawa VS, A. I. Olusanya, T. Maduku (2017). Gaming in Education: Using games as a support tool to teach History, Journal of Education and Practice, 8, 15.

Zyda, M. (2005). From visual simulation to virtual reality to games, Computer, 38, 9, 25-32, doi:10.1109/MC.2005.297. 